\title{
Challenges in the management of kidney transplant recipients in a centre without a kidney transplant program: A single centre experience
}

\author{
*Liman, H.M., Makusidi, M.A., Sakajiki, A.M., Ishaku, H.J., Shehu, Y.A., Yusuf, A.A., Yusuf, S.
}

\begin{abstract}
Objective: This study is aimed at highlighting the challenges associated with the management of kidney transplant recipients in a centre without a transplant program.
\end{abstract}

Methods: This is a retrospective study that enrolled all post renal transplant patients seen at Usmanu Danfodiyo University Teaching Hospital (UDUTH), Sokoto, North-western Nigeria between October 2010 and June 2019. Data obtained included cause of renal disease, pre-transplant dialysis details, type of donor, country of the kidney transplant, sponsor, type of maintenance immunosuppression, frequency of follow up, complications and outcome of the kidney transplant. Data obtained was analysed using statistical package for the social sciences software (SPSS) version 25 (IBM Inc. 2010).

Results: Of the 16 patients who were enrolled in this study, 10 (62.5\%) were males with a mean age of 36.5 \pm 13.2 years. Twelve (75\%) subjects reported challenges in obtaining their post-transplant immunosuppressants. Only one (6.25\%) subject had allograft biopsy despite the fact that $5(71.4 \%)$ out of the 7 patients that died had allograft dysfunction. The majority of the participants $(81.3 \%)$ had no serum tacrolimus level test done throughout their follow up period.

Conclusions: The management of post-transplant recipients in our centre is associated with challenges ranging from difficulty in procurement of post-transplant medications, poor laboratory support for monitoring of drug levels and inadequate facilities for management of allograft dysfunction.

Keywords: Kidney transplant; End-stage renal disease; follow-up

*Corresponding author

Dr Liman, H.M.

E-Mail: hamiduliman@gmail.com

Division of Nephrology, Usmanu Danfodiyo University Teaching Hospital, PMB 2370, Sokoto, Nigeria 


\title{
Défis dans la prise en charge des receveurs de transplantation rénale dans un centre sans programme de transplantation rénale: Une expérience dans un seul centre
}

\author{
*Liman, H.M., Makusidi, M.A., Sakajiki, A.M., Ishaku, H.J., Shehu, Y.A., Yusuf, A.A., Yusuf, S.
}

\section{Résumé}

Introduction : Cette étude vise à mettre en évidence les défis associés à la prise en charge des greffés rénaux dans un centre sans programme de transplantation.

Méthode de l'étude : Il s'agit d'une étude rétrospective qui a recruté tous les patients après transplantation rénale vus à l'hôpital universitaire Usmanu Danfodiyo (HUUD), Sokoto, dans le nord-ouest du Nigéria entre octobre 2010 et juin 2019. Les données obtenues comprenaient la cause de la maladie rénale, les détails de la dialyse de pré-transplantation, le type du donner, du pays de la transplantation rénale, du promoteur et d'immunosuppression. Les données obtenues ont été analysées à l'aide du progiciel statistique du logiciel de sciences sociales (PSLSS) version 25 (IBM Inc. 2010).

Résultat de l'étude : Sur les 16 patients inclus dans cette étude, 10 (62,5\%) étaient des hommes avec un âge moyen de $36,5 \pm 13,2$ ans. Douze $(75 \%)$ sujets ont signalé des difficultés à obtenir leurs immunosuppresseurs après la transplantation. Un seul sujet $(6,25 \%)$ a eu une biopsie d'allogreffe malgré le fait que $5(71,4 \%)$ des 7 patients décédés avaient un dysfonctionnement de l'allogreffe. La majorité des participants $(81,3 \%)$ n'ont eu aucun test du taux de tacrolimus sérique effectué tout au long de leur période de suivi.

Conclusion : La gestion des receveurs post-transplantation dans notre centre est associée à des défis allant de la difficulté à se procurer des médicaments post-transplantation, un soutien de laboratoire médiocre pour la surveillance des niveaux de médicaments et des installations inadéquates pour la gestion du dysfonctionnement des allogreffes.

Mots-clés: Greffe de rein, phase terminale de la maladie rénale

${ }^{*}$ Corresponding author

Liman, H.M.

E-Mail: hamiduliman@gmail.com

Division of Nephrology, Usmanu Danfodiyo University Teaching Hospital, PMB 2370, Sokoto, Nigeria 


\section{INTRODUCTION}

Chronic kidney disease (CKD) remains a major public health problem resulting in end stage renal disease (ESRD), cardiovascular disease and early mortality (1). Its prevalence has been increasing worldwide recently especially in sub Saharan Africa (2). As the number of patients with CKD rise, so does that of patients who progress to develop ESRD. Nowhere is this rise in the prevalence of ESRD worse than in sub Saharan Africa (3) which unfortunately only constitutes $5 \%$ of the total number of CKD patients who were able to access renal replacement therapy (RRT) in 2004(4). Funding for renal replacement therapy in Nigeria as in other parts of sub Saharan Africa is mainly private making chronic dialysis to be unsustainable as a result of the prevalence of poverty in the country (5). This was demonstrated in a cohort of Nigerian ESRD patients with only less than $2 \%$ of them still undergoing dialysis 12 months after its commencement (6).

Kidney transplant remains the gold standard for treatment of ESRD due to its cost effectiveness and significant improvement in the quality of life of recipients (7). However, several barriers to the achievement of universal transplantation as the therapy for ESRD exist and these include economic limitations, availability of donors and lack of expertise (8).

Nigeria, with an estimated population of about 200 million has only 15 centres capable of carrying out renal transplant surgery, majority of which are privately owned $(9,10)$. Of these 15 centres, only three of them perform more than 10 kidney transplantations per annum, leaving the vast majority of ESRD patients to either succumb to the illness or seek the procedure outside the country (10).

Of those who manage to get the kidney transplant surgery, the next barrier to renal health becomes optimal post-transplantation care (7). Due to the fact that majority of post-transplant patients in Nigeria receive care in centres where the procedure was not done, the attending physician is faced with a host of challenges such as inadequate information about the procedure, medications used in the peri-operative period and challenges faced by the transplant team during the procedure; some of which would go a long way in determining post-transplantation outcome and complication. Our centre falls in this category of hospitals where a sizeable number of post-transplant patients exist despite the absence of a renal transplant program.

This article is aimed at highlighting the challenges associated with the management of kidney transplant recipients in a centre without a transplant program.

\section{MATERIALS AND METHODS}

This is a retrospective study that enrolled all post renal transplant patients seen at Usmanu Danfodiyo University Teaching Hospital, Sokoto, North-western Nigeria between October 2010 and June 2019. The facility is an 800-bed tertiary centre serving 4 Nigerian states with an estimated population of about 15 million (11). It possesses a nephrology unit which has 3 consultant nephrologists (all of whom have considerable training in transplant nephrology) and resident doctors. But like most similar centres in the country, our centre does not undertake kidney transplantation. However, the hospital has a well-established renal dialysis program and offers various other diagnostic and therapeutic procedures including renal imaging, renal biopsy, vascular access creation and posttransplant care. Ethical clearance for this study was obtained from the human research ethics committee of the hospital.

The demographic characteristics, clinical and transplant details were obtained. These data included cause of the kidney disease, pre-transplant dialysis details, type of donor, country of the kidney transplant, sponsor of the transplant, type of maintenance immunosuppression, frequency of follow up, complications and outcome of the kidney transplant. Outcome was dichotomised into alive and dead as at the end of the study period. This information was obtained from the patient, patient's relatives as well as transplant and posttransplant follow up notes. Data was presented as frequency, mean and median as deemed relevant. Outcome of transplant was compared between transplant centres using chi-square. The effect of frequency of follow up visits on outcome of transplant was compared using student's $t$ test. $\mathrm{P}$ value of $<0.05$ was considered significant. The data was analysed using the statistical package for the social sciences software (SPSS) version 25 (IBM Inc.2010).

\section{RESULTS}

Of the 16 patients who were enrolled in the study, $10(62.5 \%)$ were males with a male to female ratio of 1.7:1. The maximum age of participants was 56 years with a mean age of $36.5 \pm 13.2$ years. The distribution of the aetiologic factors of ESRD in the subjects is as outlined in table 1 . The median number of 
haemodialysis sessions done prior to transplantation was 23 (IQR, 12 - 52.5) and they spent a median period of 123 (IQR,48.5 - 428) days on dialysis prior to their transplant. Only one patient had pre-emptive transplantation.

All the subjects had living donors with 14 $(87.5 \%)$ of the donors being related to the recipient and only $2(12.5 \%)$ of the 16 donors were females. Seven (43.8\%) subjects died posttransplant. The cumulative mean graft survival was $3.2 \pm 2.8$ years. However, the mean graft survival among the subjects who died after their transplant was much lower at $1.9 \pm 0.9$ years. Of the seven patients who died after transplant, five (71.4\%) died as a result of organ rejection, while only $2(28.6 \%)$ patients died as a result of cardiovascular events, namely stroke and myocardial infarction.

All patients in the study received induction immunosuppression before transplant. The triple post-transplant immunosuppressant combination of Tacrolimus/Mycophenolate Mofetil/Prednisolone was used in $62.5 \%$ of the subjects. Twelve (75\%) subjects reported challenges in obtaining their post-transplant immunosuppressants. Of all our patients, only one of them had allograft biopsy despite the fact that $5(71.4 \%)$ out of the 7 subjects that died had allograft dysfunction. All the patients were treated with pulse doses of intravenous methylprednisolone once daily for 3 days during each episode of graft dysfunction.

The mean number of follow up visits in the firstyear post-transplant was $4.3 \pm 1.5$ and the maximum number of visits in the same period was seven. Furthermore, only 4 (25.1\%) subjects had more than 5 visits in the first year after their procedure. Additionally, only 2 (12.5\%) subjects were seen within a month of their transplant.

Thirteen $(81.25 \%)$ subjects had no serum tacrolimus level test done throughout their follow up period making an objective assessment of their regular intake of their immunosuppressants impossible. Similarly, none of them had viral screening done during their episodes of allograft dysfunction. A total of $10(62.5 \%)$ subjects were transplanted in India, $2(12.5 \%)$ were transplanted in Egypt and $4(25 \%)$ were transplanted in Nigeria as shown in figure 1. All the patients were funded by personal and family savings. There was no statistically significant relationship between the country where the procedure was carried out and the eventual outcome $(P=0.411)$. Similarly, there was no statistically significant association between number of clinic visits in the first-year post- transplantation and patient outcome $(\mathrm{P}=0.368)$.

\section{DISCUSSION}

This study revealed that most of the patients with CKD were males and of middle age. This is similar to studies found in eastern part of the country where majority of the patients were males of middle age and low socio-economic status (12). This demographic pattern also implies that males are more likely to receive a renal transplant due to sociocultural factors in our society that favour the male gender (13).

All patients in the study are Nigerians living in Nigeria, yet only $25 \%$ of the patients had their transplant in Nigeria. India was the major country of destination for medical tourism in this study which is similar to what was found by Okafor et al (14). This can be partially explained by the relatively lower cost of renal transplant in India compared to other European countries (14). Conversely, Adamu et al found a higher percentage of transplant in Pakistan (15). This disparity can be accounted for by the scope of their study which was carried out on only commercial living unrelated organ donation which was prohibited in India in the 1990s (16).

Only one patient had pre-emptive transplant as primary renal replacement therapy. This is similar to a report in which only $2.5 \%$ of patients with ESRD had kidney transplantation as the initial modality of treatment (17). This figure has largely remained unchanged over the last decade. The donors in the study were all living donors due to unavailability of cadaveric donors for cadaveric transplant. The major source of funds for transplant was from family members buttressing the non-existent funding from government and health insurance institutions for renal transplant.

All patients in the study received induction immunosuppression before transplant probably due to recurrent blood transfusion they received before transplant. The triple combination of Tacrolimus/Mycophenolate Mofetil/Prednisolone was used in $62.5 \%$ which corresponds to the percentage of patients transplanted in India as cyclosporine, azathioprine and prednisolone were used in other centres.

One-year graft and patient survival were $81.25 \%$ and two-year graft and patient survival was $62.50 \%$. This is low compared to what was obtained in European countries who have better transplant policies and facilities (18). However, this is similar to what was found by Okafor and Arogundade in similar studies carried out in the 
country $(19,20)$.

The commonest complications were acute and chronic rejection which were difficult to manage due to absence of facilities for confirmatory diagnosis and plasmapheresis. The diagnosis was made mostly on clinical grounds based on time of presentation after the transplant and the associated clinical and biochemical features of graft rejection. Donor specific antigens were also not assayed as our laboratory does not have the relevant facility for the assessment. Of all our patients, only one of them had allograft biopsy despite the fact that 5 (71.4\%) out of the 7 patients that died had clinical and biochemical evidence of allograft dysfunction at one point or the other during their follow up period. This was partly due to high cost of the procedure and the non-availability of immunofluorescence microscopy in our centre. Protocol graft biopsy, which is fast gaining acceptance amongst transplant nephrologists worldwide, is still not routine in transplant centres in Nigeria.

Most of the subjects had no serum tacrolimus level test done throughout their follow up period. This is due to absence of the relevant machine and reagents for monitoring blood levels of calcineurin inhibitors in our facility. Other challenges to monitoring of drug levels experienced by the few subjects whose samples were taken included delay in getting results from available centres and financial constraints on patients who were already burdened by the cost of post-transplant medications. One patient had post-transplant diabetes mellitus which was managed with drug adjustment of immunosuppressants and use of oral hypoglycaemic agents. These complications are not unusual following the dearth of wellequipped laboratories for monitoring blood levels of calcineurin inhibitors. As a result, most of these drugs were not monitored as prescribed by the K-DOQI guideline.

Although 7 (44\%) of the patients in this study died from the aforementioned complications, this is by far better when compared to outcome with other forms of renal replacement therapy that are available in the country $(19,20)$.

\section{CONCLUSION}

The management of post-transplant recipients in our centre is still evolving and it is fraught with a lot of challenges ranging from procurement of post-transplant medications, available laboratories for appropriate monitoring and facilities for management of allograft dysfunction and rejection. Despite these challenges, the outcome is still better compared to other forms of renal replacement therapy.

\section{Conflict of interest: None}

\section{REFERENCES}

1. Levey A, Atkins R, Cooresh J. Chronic Kidney Disease as a global public health problem: approaches and initiatives-a position statement from Kidney Disease Improving Global Outcomes. Kidney Int. 2007;72(3):247-59.

2. Jha V, Garcia-Garcia G, Iseki K. Chronic Kidney Disease: global dimension and perspectives. Lancet. 2013;382(9888):260-72.

3. Nugent R, Fathima S, Feigl A, Chyung D. The burden of Chronic Kidney Disease on developing nations: a 21st century challenge in global health. Nephron Clin Pract. 2011;118:c269-c77.

4. Grassman A, Gioberge S, Moeller S, Brown G. ESRD patients in 2004: global overview of patient numbers, treatment modalities and associated trends. Nephrol Dial Transplant. 2005;20(12):2587-93.

5. Jungers P, Zingraff J, Page B, Albouze G, Hannedouche T, Man N. Detrimental effect of late referral in a patient with chronic renal failure: a case control study. Kidney Int Suppl. 1993;41:170-3.

6. Arogundade F, Barsoum R. Chronic Kidney Disease in sub Saharan Africa: a call for governmental, non-governmental and community support. Am J Kidney Dis. 2008;51:515-23.

7. Arogundade F, Abd-Essamie M, Barsoum R. Health related quality of life in emotionally related kidney transplantation: deductions from a comparative study. Saudi J Kidney Dis Transplant. 2005;16:311-20.

8. Tazeen J. Organ traficking: global solutions for a global problem. Am J Kidney Dis. 2009;5:114557.

9. Bamgboye E. The challenges of ESRD care in developing economies: sub-Saharan African opportunities for significant improvement. Clin Nephrol. 2016;86:18-22.

10. Bamgboye E. Update on kidney transplantation in Nigeria. (2020, Feb 17-19). Paper presented at the 32nd Annual General Meeting and Scientific Conference of the Nigerian Association of Nephrology, Ibadan, Nigeria.

11. Liman H, Makusidi A, Sakajiki A. Kidney transplant-related medical tourism in patients with end-stage renal disease: a report from a centre in a developing nation. Sahel Med J. 2020;23(1):7-11.

12. Wokoma F, Okafor U. The clinical and epidemiological characteristics of patiens treated at the haemodialysis unit of University of Port Harcourt Teaching Hospital during the first year (January to December 2007) of operation. Trop J Nephrol. 2009;1:5-7. 
13. Shamaki MA, Buang A. The Socio-cultural Behaviours of Women's Health Facilities Utilisation in Northern Nigeria. Mediterranean Journal of Social Sciences. 2015;6:517-23.

14. Okafor U. Transplant tourism among kidney transplant recepients in Eastern Nigeria. BMC Nephrol. 2017;18(1):215-21.

15. Adamu B, Ahmed M, Mushtaq R, Alshaebi F. Commercial kidney transplantation: trends, outcomes and challenges: a single-centre experience. Ann Afr Med. 2012;11:70-4.

16. Rizvi S, Naqvi S, Zafar M, Mazhar F, Muzaffar R, Naqvi R, et al. Commercial transplants in local Pakistanis from vended kidneys: a socioeconomic and outcome study. Transpl Int
2009:22(6);615-21

17. Ashby V, Kalbfleisch J, Wolfe R, Lin M, Port F, Leictman A. Geographic variability in access to primary kidney transplantation in the United States, 1996-2005. Am J Transplant. 2007: $7(2) ; 1412-23$

18. Gordon EJ, Ladner DP, Caicedo JC, Franklin J. Disparities in kidney transplant outcomes: a review. Seminars in nephrology. 2010; 30(1):819.

19. Arogundade F. Kidney transplantation in a lowincome setting: Nigerian experience. Kidney Int Suppl. 2013;3(2):241-5.

20. Okafor U. Kidney transplant in Nigeria: a single centre experience. Pan Afr Med J. 2016;25:112-7.

How to cite this article:

Liman, H.M., Makusidi, M.A., Sakajiki, A.M., Ishaku, H.J., Shehu, Y.A., Yusuf, A.A., Yusuf, S. Challenges in the management of kidney transplant recipients in a centre without a kidney transplant program: A single centre experience. Research Journal of Health Sciences, 2021, 9(1): 1-7 
Table 1: Clinical characteristics of the participants

\begin{tabular}{|c|c|c|}
\hline Variable & Result & Frequency (\%) \\
\hline Age, Mean \pm SD, Years & $35.6 \pm 13.6$ & \\
\hline \multicolumn{3}{|l|}{ Gender } \\
\hline Male & & $10(62.5)$ \\
\hline Female & & $6(37.5)$ \\
\hline \multicolumn{3}{|l|}{ Cause of ESRD ${ }^{1}$} \\
\hline $\mathrm{CGN}^{2}$ & & $8(50)$ \\
\hline Hypertension & & $5(31.3)$ \\
\hline Diabetes & & $3(18.8)$ \\
\hline Number of Dialysis Sessions before transplant, Median (IQR) & $23(12-52.5)$ & \\
\hline Duration on dialysis before transplant, Median (IQR), Days & $123(48.5-428)$ & \\
\hline \multicolumn{3}{|l|}{ Outcome } \\
\hline Alive & & $9(56.3)$ \\
\hline Dead & & $7(43.8)$ \\
\hline Graft survival, Mean $\pm \mathrm{SD}$, Years & $3.3 \pm 2.8$ & \\
\hline \multicolumn{3}{|l|}{ Donor source } \\
\hline Related & & $14(87.5)$ \\
\hline Unrelated & & $12(12.5)$ \\
\hline
\end{tabular}

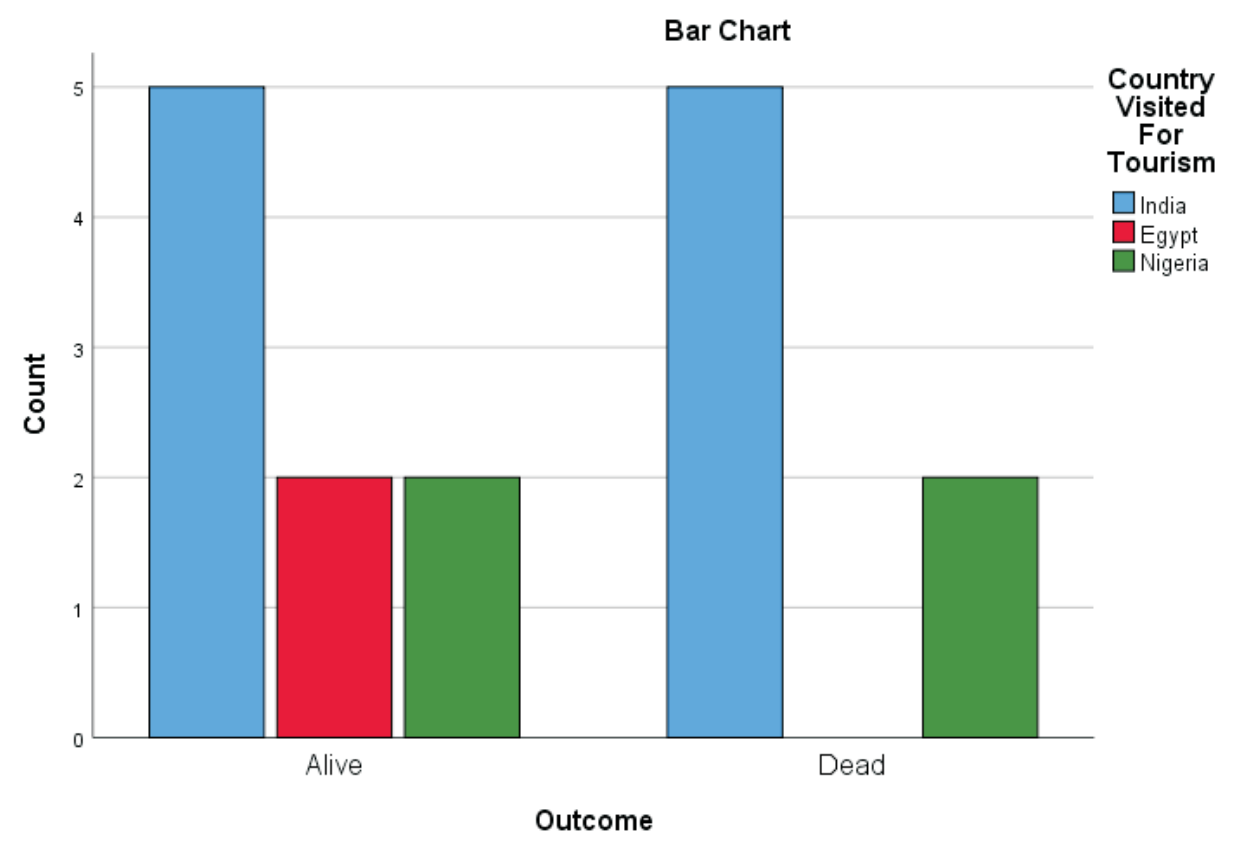

Figure 1: A cluster bar chart illustrating out come and the country where the kidney transplant was carried out. 